\title{
El traslado del coro de la iglesia de San Julián y Santa Basilisa de Samos
}

\author{
The removal of the choir of Saint Julian \\ and Saint Basilisa Church at Samos
}

Estefanía LÓPEZ SALAS

Universidade da Coruña

Recibido: 18-VII-2016

Aceptado: 5-V-2017

RESUMEN: En julio de 1967 tenía lugar el desmantelamiento y traslado del coro del templo del monasterio de San Julián de Samos (Lugo-España) de su posición original, en el primer y segundo tramos de la nave central, a la cabecera, provocando un cambio significativo en su organización espacial interior y en su arquitectura que perdura hoy en día. Entender las razones que justificaron esta actuación, conocer la imagen del espacio original perdido y analizar los proyectos diseñados para afrontar la reforma y sus consecuencias son los tres objetivos del trabajo que aquí presentamos.

Palabras clave: Arquitectura religiosa, Siglo XX, Templo monástico y parroquial, Traslado del coro, Documentación histórica, Estudio gráfico.

ABSTRACT: In July 1967 the dismantling and removal of the choir placed inside the monastic church of San Julián de Samos (Lugo-Spain) took place. It was moved from its original position, in the first and second bays of the nave, to the apse. This fact caused a significant change in its spatial interior organization and in the architecture that remains nowadays. The three aims of the work we present here are to understand the reasons that justified the transformation, to know the image of the lost original space, and to analyze the designs done to undertake the reform as well as its consequences.

Keywords: Religious architecture, 20th century, Monastic and parish church, Removal of the choir, Historical documentation, Graphic study.

En el presente artículo nos proponemos dar a conocer, de forma escrita y gráfica, la transformación experimentada por el espacio interior original del templo del monasterio de San Julián de Samos, en la segunda mitad del siglo XX, como consecuencia del traslado del coro, que ocupaba los dos primeros tramos de la nave central inmediatos al crucero, a la posición del primitivo presbiterio $^{1}$.

\footnotetext{
${ }^{1}$ Este trabajo constituye una pequeña parte de la tesis doctoral desarrollada por la autora y titulada San Julián de Samos-Lugo, estudio e interpretación del diseño monástico y su evolución, defendida en la Universidade da Coruña, en junio de 2015. Fue financiada por la Ayuda de apoyo a la etapa pre-doctoral UDC 2011 de la Universidade da Coruña y por la Ayuda de apoyo a
} 
Para alcanzar este objetivo, en primer lugar, intentamos comprender las razones que propiciaron el traslado de un elemento que, por sus dimensiones y posición, condicionaba fuertemente la distribución del conjunto del espacio. En segundo lugar, realizamos un estudio detallado de la organización primitiva del ámbito citado que hoy es un espacio perdido, es decir, del interior del templo construido en el siglo XVIII, con un coro que formaba parte solidaria de su arquitectura. Finalmente, nuestro trabajo se centra en recopilar y analizar los proyectos redactados para afrontar la reforma, los pasos dados para hacerla realidad y las consecuencias que ésta ocasionó en el espacio arquitectónico objeto de estudio hasta definir su configuración actual.

Tal y como acabamos de exponer, en este trabajo nos centramos exclusivamente en el análisis de lo ocurrido en el interior de una iglesia monacal gallega, por tanto, en una sola de las muchas actuaciones restauradoras que, con similar objetivo y resultados se llevaron a cabo en el pasado. Sin embargo, en este apartado introductorio, también conviene señalar que nuestra investigación se enmarca dentro de una línea de estudio más amplia y a la que, en los últimos años, se han hecho aportaciones cada vez más concretas. Sin pretender hacer un estado de la cuestión, pero sí con el propósito de establecer un marco general en el que ubicar este trabajo, podemos decir que el aumento del interés por el estudio de las repercusiones que la eliminación, transformación o traslado de los coros ha tenido para el interior del espacio litúrgico, se ha materializado recientemente

\footnotetext{
la etapa pre-doctoral del Plan Gallego de Investigación, Innovación y Crecimiento 2011-2015 - Plan IC2 de la Consellería de Cultura, Educación y Ordenación Universitaria de la Xunta de Galicia, cofinanciado por el Fondo Social Europeo (FSE-FEDER).

Asimismo, la autora quiere agradecer a la comunidad benedictina de San Julián de Samos, en especial a dos de sus miembros, el P. José Luis Vélez Álvarez y al P. Agustín Miguélez Vecillas, las facilidades recibidas para acceder al archivo monacal con el fin de consultar libremente multitud de documentos, planos y fotografías, sin las cuales habría sido más difícil la realización de este trabajo.
}

en varias publicaciones. De ellas destacan las de Navascués Palacio (1998, 2000), Yzquierdo Perrín (2001) y Villaseñor Sebastián y otros $(2015)^{2}$. El trabajo que a continuación se desarrolla quiere ser una contribución más a ese panorama general o, de forma más precisa, una aportación concreta sobre un caso de estudio gallego que ayude a ahondar en el conocimiento detallado de un tipo de intervenciones restauradoras con enormes repercusiones en el patrimonio arquitectónico hoy conservado.

\section{INTENTANDO JUSTIFICAR EL TRAS-} LADO

La primera referencia a la idea de reformar el interior del templo de Samos la encontramos en una memoria redactada en enero de 1959, por un miembro de la comunidad monacal, y que hoy se conserva en el Archivo del Monasterio de Samos. El documento al cual nos referimos se titula Memoria de las obras y mejoras efectuadas desde 1930 a 1959. En su último folio contiene un apartado en el que, bajo el título Proyectos preparados para su ejecución, se recoge la "Reforma y cambio del emplazamiento del coro bajo de la Iglesia, que, en el sitio actual, entorpeciendo la visibilidad de los Divinos Oficios, reduce considerablemente el espacio útil del espacioso templo a dimensiones en que con dificultad pueden acomodarse los fieles que concurren en las festividades" ${ }^{\prime 3}$.

Pocos años después, en febrero de 1965, Mauro Gómez Pereira, como abad del monasterio, le envió una carta al Director General de Bellas Artes, en la que, de nuevo, se

\footnotetext{
${ }^{2}$ P. NAVASCUÉS PALACIO, Teoría del coro en las catedrales españolas, Madrid, 1998; ÍDEM, "Coros y sillerías: un siglo de destrucción", Descubrir el Arte, no 15, 2000, pp. 112-114; R. YZQUIERDO PERRÍN (ed.), Los coros de catedrales y monasterios: arte y liturgia, A Coruña, 2001; F. VILLASEÑOR SEBASTIÁN, M. D. TEIJEIRA PABLOS, W. MULLER y F. BILLIET (eds.), Choir Stalls in Architecture and Architecture in Choir Stalls, Newcastle upon Tyne, 2015.

${ }^{3}$ Archivo del Monasterio de Samos (en adelante AMS), Papeles del tiempo del abad Mauro Gómez Pereira (1930-1972), Carpeta F10, Memoria de las obras y mejoras efectuadas desde 1930 a 1959, enero de 1959, sin foliar.
} 
señala como obra muy necesaria el traslado del coro bajo del templo, desde su emplazamiento original al presbiterio, "con el fin de que la iglesia tenga toda su capacidad, muy mermada por el sitio que ahora ocupa el coro y la falta de visibilidad del altar, resultando actualmente insuficiente para los fieles que acuden al templo" ${ }^{4}$.

En ambos casos vemos que para justificar la necesidad de trasladar el coro, la comunidad monacal se apoyó fundamentalmente en dos cuestiones de carácter funcional. Por un lado, en la consideración de que la posición del coro en la nave central reducía, de forma notable, la superficie útil del templo y, por otro, en el hecho de que su presencia se creía que entorpecía la visibilidad del altar, ubicado bajo el retablo principal, en particular en el caso de los fieles que acudían a la liturgia, pues el templo de Samos era y es no sólo un templo monástico, sino también parroquial $^{5}$.

Estas dos razones pueden relacionarse con los nuevos planteamientos litúrgicos promovidos por el Concilio Vaticano II, en la segunda mitad del siglo $X^{6}$. La Constitu-

${ }^{4}$ B. M. CASTRO FERNÁNDEZ, Francisco PonsSorolla y Arnau, arquitecto-restaurador: sus intervenciones en Galicia (1945-1985), Santiago de Compostela, 2007, pp. 534-535.

${ }^{5}$ La iglesia nueva del monasterio, la actual, continuó manteniendo la función de parroquial que ya poseía el templo románico preexistente. El "Auto de erección de la parroquia" fue firmado el 15 de julio de 1684 por el abad fray José Valdés, declarando como altar parroquial el dedicado a Santa Gertrudis, en ese momento situado en el extremo norte del crucero de la hoy desaparecida iglesia románica del monasterio. M. CASTRO, "Un monasterio gallego", Boletín de la Comisión Provincial de Monumentos Históricos y Artísticos de Orense, IV, nº 85, 1912, pp. 192-194; P. ARIAS ARIAS, Historia del Real Monasterio de Samos, Santiago de Compostela, 1950, p. 233; P. DE LA PORTILLA COSTA, "San Julián de Samos", en Monasterios de España, Madrid, 1988, pp. 2588; E. LÓPEZ SALAS, "Propuesta metodológica para la restitución de la planimetría de una arquitectura medieval desaparecida: la iglesia románica del monasterio de San Julián de Samos (Lugo)", Arqueología de la Arquitectura (en línea), nº 10, e002, Madrid/Vitoria, 2013, pp. 14 y 16, consultado el 21 de abril de 2014. URL: http://dx.doi.org/10.3989/arq.arqt.2013.008.

${ }^{6}$ Así lo plantean M. ARIAS CUENLLAS, Historia del monasterio de San Julián de Samos, Samos, 1992, p. 506; A. GARRIDO MORENO, "Juan Monleón Sapiña. Proxectos ción sobre la Sagrada Liturgia, Sacrosanctum Concilium, aprobada por los padres conciliares para promover la renovación litúrgica en diciembre de 1963, recogía, entre otros principios, el siguiente: "Al edificar los templos, procúrese con diligencia que sean aptos para la celebración de las acciones litúrgicas y para conseguir la participación activa de los fieles"7. Por tanto, esta reforma litúrgica convertía a los fieles en los principales beneficiarios de la adaptación de los lugares de culto, pues se daba más valor a las personas que a los objetos, intentando que todos los elementos del edificio eclesial y todos los lugares en los que se desarrollaba la celebración estuviesen realmente al servicio de aquellos ${ }^{8}$. Así lo pone de manifiesto la lectura del capítulo quinto de la primera Instrucción publicada en septiembre de 1964, para la aplicación correcta de la Constitución sobre la Sagrada Liturgia, conocida como Inter Oecumenici?. En ella se relacionan los principios generales para conseguir la renovación, a través de una nueva forma de entender y organizar los objetos en el interior del templo, con el objetivo principal de facilitar la participación activa de los fieles.

El primer principio de la renovación promovida por el capítulo quinto de esta primera Instrucción establecía lo siguiente: "Al construir nuevas iglesias, al reconstruirlas o adaptarlas, procúrese con diligencia que resulten adecuadas para celebrar las acciones sagradas, conforme a su auténtica naturaleza, y obtener la participación activa

e reformas no mosteiro de Samos (1951-1976)", en M. C. FOLGAR DE LA CALLE y A. E. GOY DIZ (dirs.), San Xulián de Samos: Historia e arte nun mosteiro. Opus Monasticorum III, Santiago de Compostela, 2008, p. 189.

Sacrosanctum Concilium, cap. VII, art. 124, consultado el 25 de agosto de 2015. URL: http://www. vatican.va/archive/

${ }^{8}$ Secretariado Nacional de Liturgia (ed.), Directorio litúrgico-pastoral sobre ambientación y arte en el lugar de la celebración, Madrid, 1987, pp. 5-6.

9 Inter Oecumenici, consultado el 25 de agosto de 2015. URL: http://www.vicariadepastoral.org.mx/ liturgica/estudio_liturgico/inter_oecumenici.pdf 
de los fieles"10. Para lograr ese objetivo, los siguientes números de la Instrucción recogen las pautas a seguir en la ambientación del espacio litúrgico y la disposición correcta de todos los objetos sagrados.

En primer lugar, la Instrucción indica que el altar mayor debía construirse separado de la pared, "de modo que se pueda girar fácilmente en torno a él y celebrar de cara al pueblo"11. Asimismo, se apunta que debía "ocupar un lugar tan importante en el edificio sagrado que sea realmente el centro adonde espontáneamente converja la atención de toda la asamblea de los fieles"12. De igual modo, la amplitud del presbiterio en torno al altar tenía que ser suficiente para poder desarrollar de forma cómoda los ritos relacionados con la celebración litúrgica.

La Instrucción establece una sede fija para el celebrante. Mientras que antes tan sólo existía una sede para el obispo, ahora el sacerdote que celebra la liturgia también dispone de ella. Sobre su posición dentro del espacio del templo, la Instrucción señala que debe colocarse de forma que "según la estructura de cada iglesia, sea bien visible a los fieles, y el celebrante aparezca realmente como el presidente de toda la comunidad de los fieles"13.

En tercer lugar, se defiende la existencia de un único altar lo que conduce a la reducción del número de altares laterales que, en el caso de existir, deben estar situados en capillas separadas del cuerpo de la iglesia ${ }^{14}$. Asimismo, dentro del espacio litúrgico, se señala la conveniencia de colocar uno o dos ambones en los que proclamar las lecturas sagradas, "dispuestos de tal forma que los fieles puedan ver y oír bien al ministro"15.

\footnotetext{
${ }^{10}$ Ibídem, cap. V, art. 90.

${ }^{11}$ Ibídem, cap. V, art. 91.

${ }^{12}$ Ibídem.

${ }^{13}$ Ibídem, cap. V, art. 92.

${ }^{14}$ Ibídem, cap. V, art. 93.

${ }^{15}$ Ibídem, cap. V, art. 96.
}

Aunque la organización de todos los elementos señalados hasta ahora -altar principal, presbiterio, sede del celebrante y ambón-, dentro del templo, se plantea claramente para centrar la atención en lo fundamental y favorecer la participación, uno de los últimos puntos de esta Instrucción señala, de forma expresa, la importancia de tener especial cuidado en "disponer el lugar de los fieles de modo que puedan ver las celebraciones sagradas y participar debidamente en ellas"16. Para dicho fin se indica la conveniencia de colocar bancos o sillas para su uso, procurando que "los fieles no sólo puedan ver al celebrante y demás ministros, sino también escucharlos cómodamente, utilizándose para ello los medios técnicos modernos ${ }^{\prime 17}$.

En resumen, la idea de promover una mayor participación del pueblo en la liturgia fue entendida, en muchos casos, como una necesidad insoslayable de adaptar los antiguos lugares de culto a unos nuevos planteamientos litúrgicos. Sin embargo, la aplicación estricta de esta reforma hubiera dejado sin uso un número importante de templos que, por su arquitectura y organización, no podían ser receptores de la adaptación litúrgica planteada.

De hecho, si profundizamos en la lectura del capítulo séptimo de la Constitución sobre la Sagrada Liturgia, Sacrosanctum Concilium, podemos ver claramente que no sólo se hace referencia a la necesidad de edificar templos aptos para la liturgia y para alcanzar una activa participación de los fieles, tal $\mathrm{y}$ como hemos señalado anteriormente. Al mismo tiempo, en el punto 123 se determina la obligación de la Iglesia de conservar su patrimonio, sea cual sea el momento en el que éste fue producido, de la siguiente forma: "La Iglesia nunca consideró como propio ningún estilo artístico, sino que acomodándose al carácter y condiciones de los pueblos y a las necesidades de los diversos ritos, aceptó las formas de cada tiempo, creando

\footnotetext{
${ }^{16}$ Ibídem, cap. V, art. 98.

${ }^{17}$ Ibídem.
} 
en el curso de los siglos un tesoro artístico digno de ser conservado cuidadosamente" ${ }^{\prime 18}$.

Por ello, el desmantelamiento y traslado del coro del templo de Samos, un hecho que fue común en otros muchos templos de las órdenes monásticas y también en no menos iglesias seculares en los siglos XIX y XX, no puede justificarse por el cumplimiento estricto de una serie de disposiciones derivadas del Concilio Vaticano II, tal y como bien apunta Navascués Palacio al estudiar la pérdida o traslado de los coros en diversas catedrales españolas ${ }^{19}$.

No obstante, aunque el estricto cumplimiento de unas disposiciones conciliares no puede ser considerado el motivo de la significativa transformación de un espacio litúrgico como el de Samos, en nuestro caso de estudio sí es fácil ver que los principios para la renovación litúrgica promovidos a través de la Constitución Sacrosanctum Concilium y de la Instrucción Inter Oecumenici, estuvieron muy presentes en la mente de aquellos que propiciaron la reforma y en los fines que buscaban alcanzar con los cambios realizados, tal y como el análisis que realizaremos a continuación nos permitirá constatar.

\section{EL ESPACIO INTERIOR DEL TEMPLO ANTES DE LA REFORMA}

Desde julio de 1748, fecha de la consagración de la actual iglesia de $\operatorname{Samos}^{20}$, hasta el mismo mes del año 1967, momento en el que dio inicio el desmontaje y traslado del antiguo $\mathrm{corO}^{21}$, la organización del interior del templo se mantuvo sin grandes cambios $^{22}$. Aunque este lugar de culto hoy se en-

18 Sacrosanctum Concilium, cap. VII, art. 123, consultado el 25 de agosto de 2015. URL: http://www. vatican.va/archive/

${ }^{19}$ P. NAVASCUÉS PALACIO, Teoría del coro...., pp. 129-131.

${ }^{20}$ P. ARIAS ARIAS, Op. cit., p. 266.

${ }^{21}$ M. ARIAS CUENLLAS, Op. cit., p. 506.

22 Entre la documentación localizada consta la realización, entre 1930 y 1959, de una reforma del coro de la iglesia, de la que se dice que consistió en colocar "en él entarimado de madera, restaurando la Sillería cuentra radicalmente transformado, el conocimiento de cómo se distribuyó en el pasado es posible recurriendo a fuentes de diversa índole.

La primera de ellas es de tipo documental. Se trata del testimonio escrito de cuatro estudiosos del monasterio, que vieron y describieron el interior del templo a finales del siglo XIX y principios del XX. Con anterioridad a ellos, sólo hemos podido localizar una pequeña descripción del coro, no por ello menos interesante, en el llamado Inventario de los vienes y efectos ecsistentes hallados en el monasterio de Samos en el momento de su desamortización, redactado el 29 de abril de 1836. En este documento se dice del coro primitivo lo siguiente:

"Se halla situado en el medio de la yglesia, cerrada su entrada con valaustrado de yerro con su cerradura y llabe; hay en el sesenta y cinco sillas fijas, un facistol grande, un belón de bronce, tres atriles de archiconar, tres berbiarios [sic], veinte y tres procesionarios, diez y ocho libros de coro de a bara castellana de largo y tres cuartas de ancho con sus ojas de pergamino, tres estalnas pequeñas de las virtudes teologales, $\mathrm{y}$ un san Benito en la parte inferior que cierra el coro. Hay las estatuas de Argérico y Orgilión, abades, que constituyen las armas del Monasterio, y las de los reyes D. Fruela y D. Alonso el Casto" ${ }^{23}$.

antigua y la ampliación de la misma". AMS, Papeles del tiempo del abad Mauro Gómez Pereira (1930-1972), Carpeta F10, Memoria de las obras y mejoras efectuadas desde 1930 a 1959, enero de 1959, sin foliar. Con respecto a esta reforma, Arias Cuenllas añade que "se niveló el pavimento de madera, que aún hoy se conserva, y se colocaron antepechos-reclinatorios delante de cada uno de los grupos de sitiales de la parte baja [...]". M. ARIAS CUENLLAS, Op. cit., p. 487. A ello también hace referencia P. DE LA PORTILLA COSTA, Monasterio de San Julián de Samos. Historia de dos restauraciones (1880 y 1951), A Coruña, 2003, pp. 35-36.

23 Archivo Histórico Provincial de Lugo (en adelante AHPL), Fondo Desamortización, Inventario III, signatura 18470, sin foliar. La transcripción de este documento ha sido reproducida en M. C. FOLGAR DE LA CALLE y A. E. GOY DIZ (dirs.), Op. cit., Apéndice documental [CD-ROM]. 
Tras esta pequeña descripción del coro original del templo de Samos, el primer autor en profundizar un poco más en su conocimiento, junto a un estudio paralelo de otros elementos de la iglesia, fue Bartolomé Teijeiro Sanfiz en $1887^{24}$, diciendo lo siguiente:

"El coro destinado a los oficios divinos ocupa la parte media inferior de la nave de en medio. Su sillería, sin estar mal construida, no es de un mérito extraordinario; pero en la parte que cierra el coro por la espalda, son notables las estatuas de tamaño igual al natural conque tropieza el observador despues de pisar el umbral de la puerta principal, dando frente al frontís del trascoro. Dos de ellas representan los primeros monges que vinieron huyendo de Toledo perseguidos por los sarracenos, [...] Otras dos recuerdan la estancia en la casa de D. Alfonso el Casto y D. Fruela. Entrambos fueron educados en el convento, y aquel no solamente estuvo, siendo niño, sinó que permaneció despues recogido, huyendo de la tiranía de Mauregato, habiendo sido expulsado del Reino últimamente por los tiranos. Por regla general todas las estatuas, que se reconocen en la Iglesia, son de un trabajo concienzudo" 25 .

El segundo texto que vamos a reproducir pertenece a Manuel Castro y forma parte de un estudio mayor elaborado por este autor en 1912 sobre el conjunto del monasterio $^{26}$. De todas las descripciones conservadas sobre el antiguo coro de la iglesia actual de Samos, esta es quizás la más interesante para llevar a cabo la reconstrucción del estado original del conjunto de este lugar de culto antes de su reforma a mediados del siglo XX:

“El interior del templo, vasto rectángulo de 51 metros de longitud por 27 de ancho,

24 B. TEIJEIRO SANFIZ, Breve reseña históricodescriptiva de la Catedral de Lugo, las iglesias de Santo Domingo y San Francisco, pertenecientes a los conventos del mismo nombre, y del monasterio de san Julián de Samos, Lugo, 1887, pp. 45-50.

\footnotetext{
${ }^{25}$ Ibídem, p. 47.

${ }^{26}$ M. CASTRO, Op. cit., pp. 163-167.
}

dividido en tres naves, forma con la central y el transepto una cruz latina realzada por airosa cúpula hemisférica de unos 30 metros de elevación.

$\mathrm{Al}$ atravesar el soberbio cancel de artesonado techo y tallada puertas, ornado exteriormente con las armas de España e interiormente con las de la casa, se halla una especie de vestíbulo con bóveda casi plana, comprendida entre las torres y dos grandes arcos elípticos paralelos a la fachada. Dos pequeñas puertas lo ponen en comunicación por derecha e izquierda con el primer compartimiento de las naves laterales, mientras que el vano del frente pone de manifiesto parte de la nave central.

Lo primero en que tropieza la vista es el muro del trascoro, sobre el cual y en medio se ostenta en gran tamaño el escudo cuartelado de la casa.

Está timbrado con sombrero de cinco borlas, dispuestas una, tres y una. Le sirven de tenantes los abades Argerico y Ofilon, vestidos con amplias cogullas y apoyados en los báculos. A uno y otro lado D. Fruela I y D. Alonso el Casto, con las espadas desnudas y alzadas en actitud de combatir, completan el noble coronamiento de aquel estorbo, que ni la gallardía de las estatuas, ni la belleza del conjunto, con ser grandes, pueden hacer tolerable. [...].

Ocupa el coro dos cláusulas de la nave central, y está separado del transepto por una verja de hierro de unos 2'50 metros de altura. Las sillas, en número de 56, y dispuestas en dos órdenes, no ofrecen de notable más que su extremada sencillez y harmónicas proporciones; carecen de umbela, $y$ casi todo su decorado, si se exceptúa la serie de simbólicos flameros que exornan la cornisa sobre el respaldo de las sillas altas, se reduce a molduras lisas empleadas con tanta sobriedad como buen gusto.

Llaman en cambio la atención de un modo especial las estatuas alegóricas de las virtudes teologales, que ocupan, con dos hermosos niños cada una, las acróteras de 
tres frontoncitos triangulares, sostenidos por columnas dóricas y distribuidos simétricamente en los costados y fondo entre los asientos superiores.

El facistol, pieza sólida y de buen corte, es de la misma época y labor que la sillería. Tiene cuatro caras y termina en un templete con un pequeño crucifijo encima $[\ldots]^{\prime 27}$.

De 1947 es la tercera descripción conservada sobre el antiguo coro de Samos dentro de la bibliografía existente. Fue elaborada por el arquitecto Miguel Durán:

“La sillería del coro ocupa un espacio de la nave central próximo al crucero, al modo que es usual en muchos de nuestros templos catedralicios. Sobre el altar del trascoro y coronando su testero vemos el escudo de la orden sostenido por los abades Agerico y Offilón, y a los lados las esculturas de los reyes fundadores y protectores de Samos, Don Fruela I y Don Alfonso II el Casto" ${ }^{28}$.

En último lugar, reproducimos parte de las palabras escritas en 1950 por el monje Plácido Arias Arias sobre lo que él denomina "Interior [del templo de Samos] visto desde el cancel", donde concentra su atención en el trascoro y los altares del interior del templo, pero no en la sillería del coro y su organización:

"Subimos la escalinata hecha en el 1779, que nos recuerda la del Obradoiro de Compostela, y pasado el severo cancel, ornado al exterior con las armas de España y al interior con las del Monasterio, nos detenemos un instante para contemplar lo que se ofrece a nuestros ojos.

Primeramente, el muro del trascoro sobre el cual, y en el medio, se ostenta en gran tamaño el escudo cuartelado de la Casa. Lleva el primer cuartel la histórica Cruz de Samos, tan famosa en las pasadas centurias. El segundo, una espada y una palma que enfila una corona de oro, emblemas del martirio de

\footnotetext{
${ }^{27}$ Ibídem.

${ }^{28}$ M. DURÁN, La Real Abadía de San Julián de Samos: estudio histórico-arqueológico, Madrid, 1947, pp. 40-42.
}

San Julián y de la pureza de ambos esposos. En el tercero, se ve un pórtico por donde entra un ave portando en el pico un anillo. [...] En el cuarto, están representados el ciprés, todavía existente en el día de hoy, y un laurel que desapareció bien entrado ya el siglo XX $[\ldots]^{\prime \prime 29}$.

Estas son las únicas referencias que nos muestran una imagen escrita del desaparecido coro de Samos antes de julio de 1967, así como del aspecto del interior del templo que fue construido a mediados del siglo XVIII. A través de ellas obtenemos una serie de datos que nos permiten hacer una primera aproximación al conocimiento de un espacio perdido. Al mismo tiempo, la lectura de estos textos nos deja reconocer la diferente valoración que, de un mismo elemento, hicieron un conjunto de estudiosos en un periodo temporal concreto.

La segunda fuente para estudiar el interior original del templo de Samos es de tipo planimétrico. Se trata de la planta del monasterio publicada por Miguel Durán en $1947^{30}$ y que fue dibujada por este mismo autor pocos años antes, en 1942 (Fig. 1). Incluye la representación del nivel bajo de los dos claustros y también la planta de la iglesia, a la altura del primer nivel del claustro grande, con la organización que esta tenía desde el siglo XVIII. Es un documento fundamental para entender cómo el coro era el corazón del espacio litúrgico del templo monástico de Samos, condicionando su forma y constituyendo un elemento primordial del proyecto desde su concepción.

La tercera y última fuente de datos de la que disponemos, para el alcance del objetivo planteado, la constituyen las fotografías que se conservan del interior del templo, de la primera mitad del siglo XX (Figs. 2, 3, 4 y 5). Aunque no son muy numerosas, ofrecen una información valiosa de cómo era realmente

\footnotetext{
${ }^{29}$ P. ARIAS ARIAS, Op. cit., pp. 423-430.

${ }^{30}$ M. DURÁN, Op. cit., Fig. I.
} 


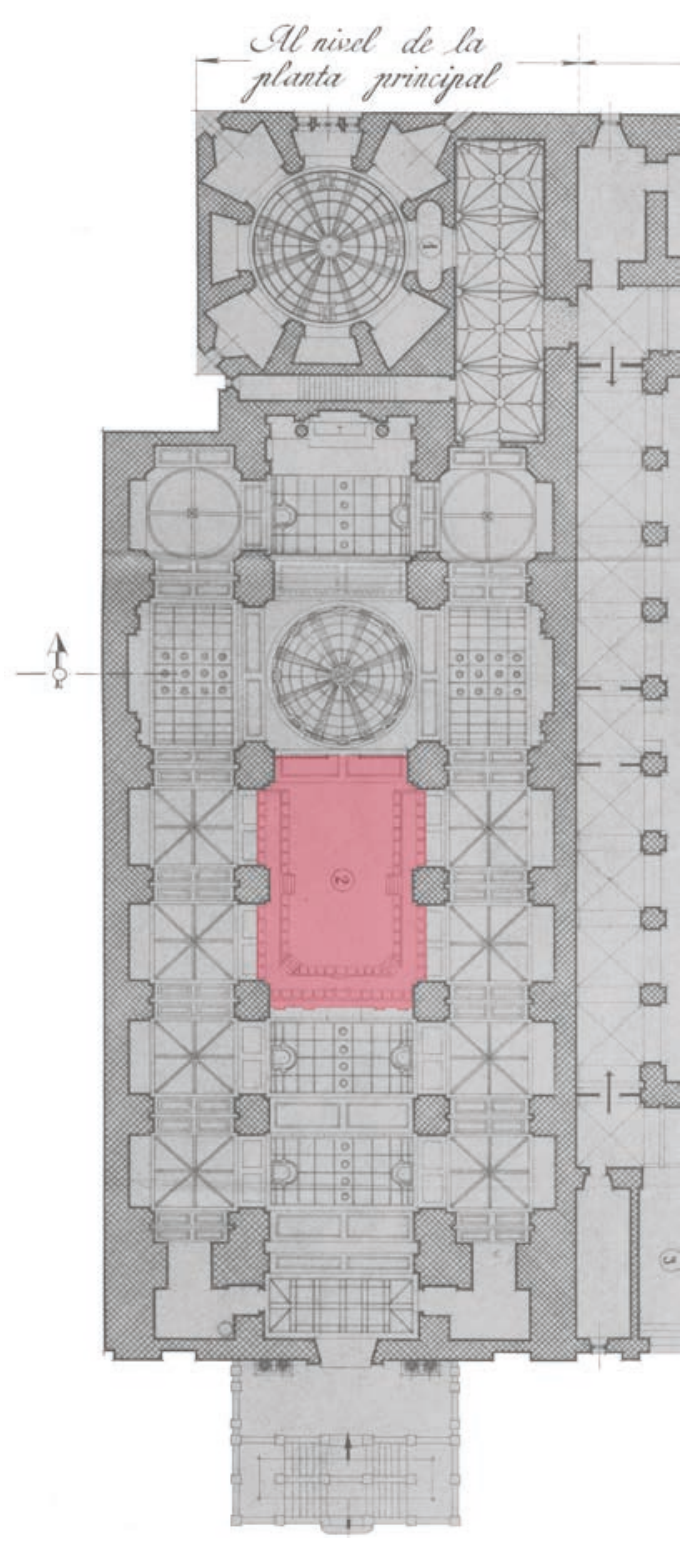

- Fig. 1. Planta de la iglesia del monasterio de Samos dibujada en 1942 por el arquitecto Miguel Durán, donde se refleja su organización interior original y señalamos en color rojo el ámbito del coro. Publicada en M. DURÁN, La Real Abadia de San Julián de Samos: estudio históricoarqueológico, Madrid, 1947.

la distribución original de ese espacio litúr-

gico, hoy perdida en su mayor parte ${ }^{31}$.

\footnotetext{
${ }^{31}$ Por una cuestión de limitación de espacio, no todas las imágenes conservadas del interior de la iglesia de Samos antes de 1967 han sido reproducidas en este trabajo.
}

Si sumamos la información obtenida por las tres vías de aproximación, documental, planimétrica y fotográfica, podemos recrear el estado original del interior del templo. El coro de los monjes se concibió ocupando los dos primeros tramos de la nave central, contando desde el crucero. La sillería se dispuso formando una doble $\mathrm{U}$, que se abría hacia el altar mayor. Entre el crucero y el espacio del coro, reservado exclusivamente a los monjes de la comunidad, se colocó una reja de hierro como elemento de separación. Tras la sillería del coro, entre las dos pilastras que separan el segundo del tercer tramo de la nave central, se levantó un muro o trascoro que contenía el altar para los fieles. Entre la puerta de entrada a la iglesia desde el exterior y el trascoro, se desarrollaba el espacio destinado a los feligreses. En definitiva, la organización inicial seguía el modelo que Navascués Palacio denomina de altar-fieles en celebraciones solemnes, coro-trascorofieles en celebraciones ordinarias ${ }^{32}$.

Desconocemos el momento exacto en el que el coro que estamos analizando fue construido, pero seguramente fue una tarea pensada y ejecutada junto al proyecto de la nueva iglesia, pues la forma de resolver la cara interior de las pilastras que separan la nave central de las laterales, es distinta en los dos tramos destinados al coro, que en aquellos otros que fueron proyectados para quedar a la vista ${ }^{33}$ (Fig. 6). Por tanto, el coro ya debía estar en su posición original en el momento de la consagración del templo, el 8 de julio de $1748^{34}$. A partir de esa fecha

32 P. NAVASCUÉS PALACIO, “Los coros catedralicios españoles", en R. YZQUIERDO PERRÍN (ed.), Op. cit., p. 30.

${ }^{33}$ Portilla Costa señala que "Las cuatro pilastras centrales no llegan hasta el suelo, porque el coro ocupaba este lugar antes de la reforma de 1967-1968". P. DE LA PORTILLA COSTA, Monasterio de Samos Guía histórico-artística, Lugo, 1978, p. 29; ÍDEM, El monasterio de Samos. Madrid, 1984, p. 42.

34 P. ARIAS ARIAS, Op. cit., p. 266; M. ARIAS CUENLLAS, Op. cit., p. 276. Para hacer referencia a la fecha de consagración del nuevo templo de Samos, Arias Cuenllas cita a Arias Arias, aunque comete un 


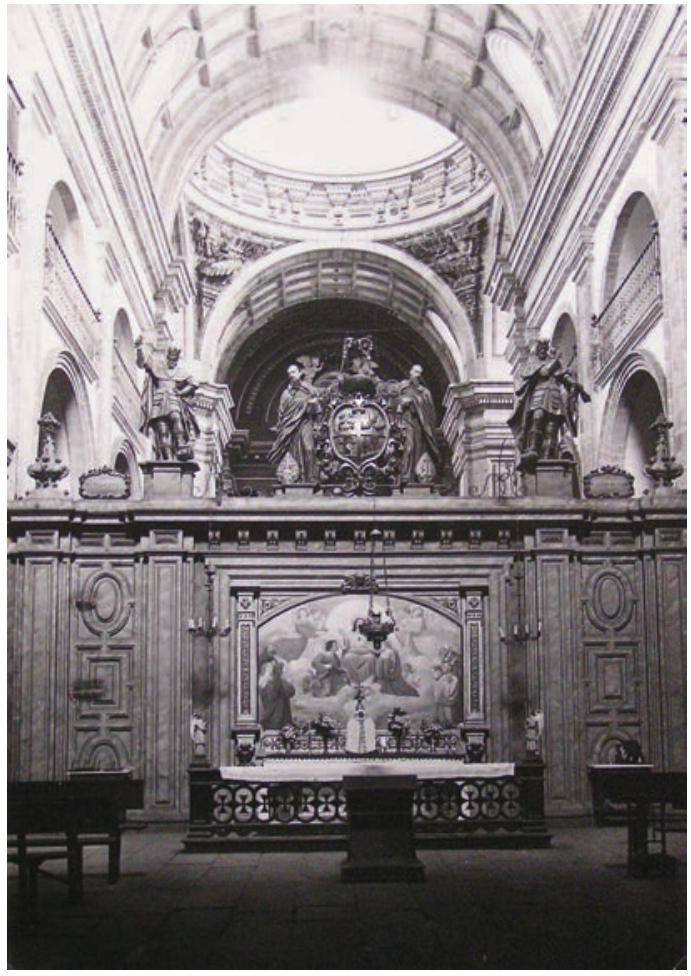

- Fig. 2. Interior de la nave central visto desde la puerta de entrada al templo y mirando en dirección al trascoro, hacia 1947. Fondo Fotográfico del Monasterio de Samos.

sabemos que se continuó con los trabajos de acondicionamiento del resto del espacio interior, en el periodo que transcurrió entre 1749 y $1785^{35}$.

Durante el gobierno del abad fray Eladio de Nóboa (1749-1753), se pavimentó con losas de granito el templo ${ }^{36}$, reutilizando algunas de las de la antigua iglesia románica, colocadas en su mayoría frente a los viejos retablos de la Inmaculada y de San Benito, piezas realizadas por Francisco de Moure, y también trasladadas de la iglesia románica a la nueva. Asimismo, se elaboraron cuatro estatuas para coronar el muro del trascoro, de los reyes Fruela I y Alfonso II el Casto y de

error al hablar del 11 de julio en lugar del 8 de julio de 1748.

\section{${ }^{35}$ M. ARIAS CUENLLAS, Op. cit., p. 277.}

${ }^{36}$ P. ARIAS ARIAS, Op. cit., p. 311. A excepción del área correspondiente al coro que fue pavimentada en madera, tal y como se conserva hoy en día. los abades Argerico y Ofilón ${ }^{37}$. Este dato nos permite suponer que si fray Eladio de Nóboa dirigió la ejecución de dichas estatuas para decorar el trascoro, el coro de los monjes ya debía estar realizado con anterioridad, pues de lo contrario no se preocuparían por ennoblecer el trascoro, dato que, de nuevo, incide en la idea de concepción simultánea del coro dentro del conjunto del proyecto del templo.

Los múltiples retablos que alberga el templo, excepto aquellos que se aprovecharon del antiguo, son resultado del trabajo de distintos escultores a lo largo de varios $\operatorname{años}^{38}$. Los que ocupan los dos extremos del crucero, dedicados a la Virgen y a San Benito, Arias Cuenllas los atribuye al escultor

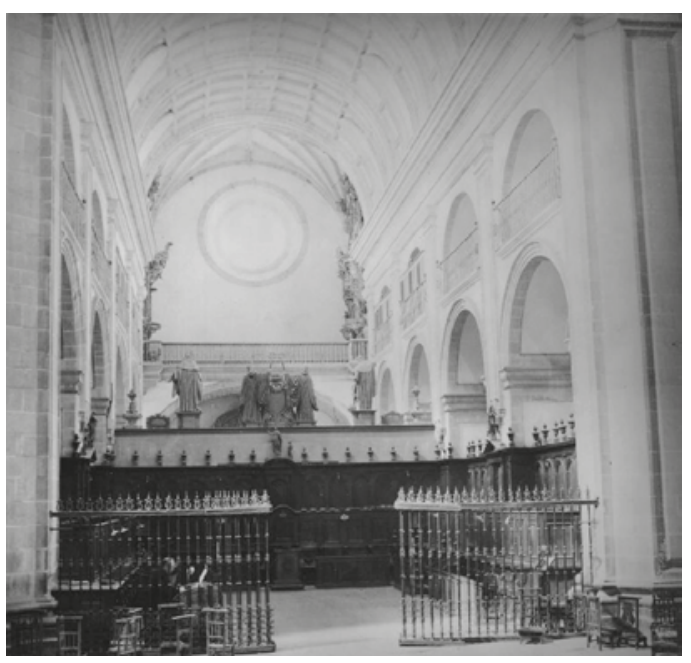

- Fig. 3. Vista del coro situado en los dos primeros tramos de la nave central, en la primera mitad del siglo XX. Fototeca de la Universidad de Sevilla, nº de registro: 007999.

${ }^{37}$ M. ARIAS CUENLLAS, Op. cit., p. 277.

${ }^{38}$ Sobre los retablos del templo actual de Samos se puede consultar: M. CASTRO, Op. cit., pp. 163171; P. ARIAS ARIAS, Op. cit., pp. 426-431; P. DE LA PORTILLA COSTA, Monasterio de Samos Guía..., pp. 28-39; ÍDEM, El monasterio de San Julián de Samos..., pp. 42-54; M. ARIAS CUENLLAS, Op. cit., pp. 277-278 y 542-544; J. M. B. LÓPEZ VÁZQUEZ, “Os retablos neoclásicos do mosteiro de Samos", en M. C. FOLGAR DE LA CALLE y A. E. GOY DIZ (dirs.), Op. cit., pp. 223237; I. REGA CASTRO, "A(s) igrexa(s) de San Xulián de Samos. O seu amoblamento durante o Barroco", en M. C. FOLGAR DE LA CALLE y A. E. GOY DIZ (dirs.), Op. cit., pp. 209-222. 


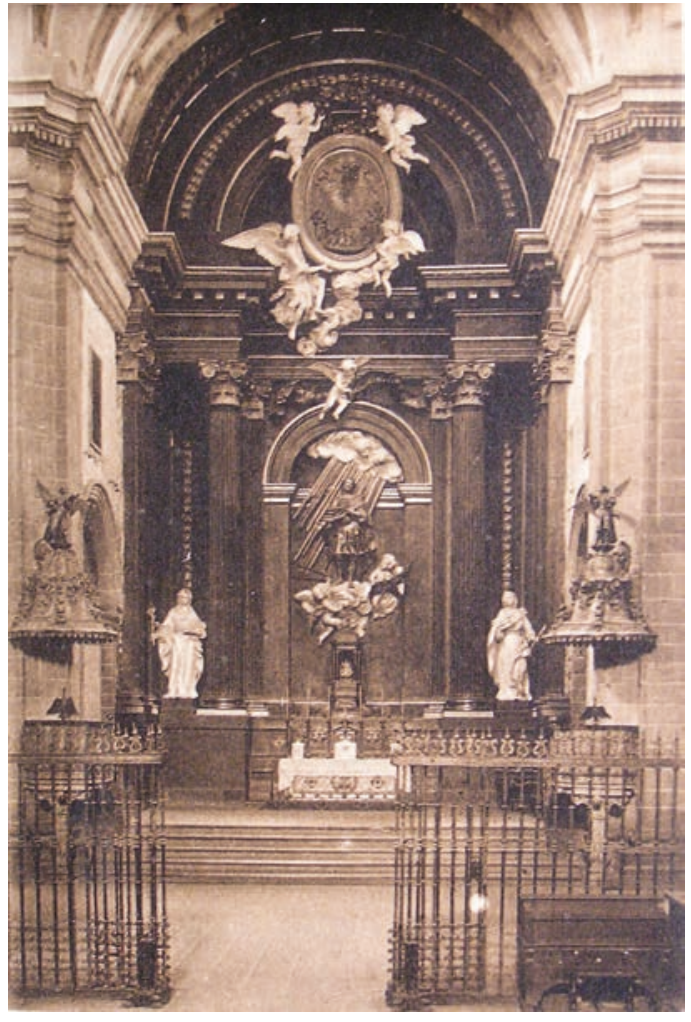

- Fig. 4. El presbiterio y el altar mayor vistos desde el coro, hacia 1924-1925. Publicada en Recuerdo de la Abadía de Samos, Madrid, sin fecha.

Gregorio Durán, que los elaboraría durante el abadiato de fray Eladio de Nóboa (1749$1753)^{39}$. Otros cuatro retablos situados en las naves laterales, dedicados a San Rosendo, Santa Escolástica, San Blas y San Eufrasio, los realizó el escultor José Ferreiro, durante el periodo de gobierno de fray Miguel Benito Gayoso (1781-1785), al igual que el nuevo retablo de la capilla mayor ${ }^{40}$.

El interior de la iglesia de Samos se mantuvo, tal y como recogen las palabras anteriores, hasta mediados del siglo XX, cuando la decisión de trasladar el coro de su posición original a la del antiguo presbiterio provocó un cambio en la disposición del lugar de celebración y lo transformó definitivamente.

\footnotetext{
${ }^{39}$ M. ARIAS CUENLLAS, Op. cit., p. 278.

${ }^{40}$ Ibídem.
}

\section{LA CONFIGURACIÓN DE UN NUE- VO ESPACIO LITÚRGICO: PROYEC- TOS, OBRAS Y CAMBIOS}

Aunque la idea de reformar el interior del templo ya estaba presente en la mente de la comunidad monacal desde 1959, tanto la redacción del proyecto como su ejecución se prolongaron en el tiempo. El encargado de redactar el proyecto fue Juan Monleón Sapiña, arquitecto e ingeniero valenciano, que ingresara como oblato regular en el monasterio de Samos en julio de $1951^{41}$.

Antes de llegar a una solución definitiva, Juan Monleón estudió varias opciones de organización del espacio (Fig. 7) ${ }^{42}$. Los planos de las diversas variantes del proyecto se

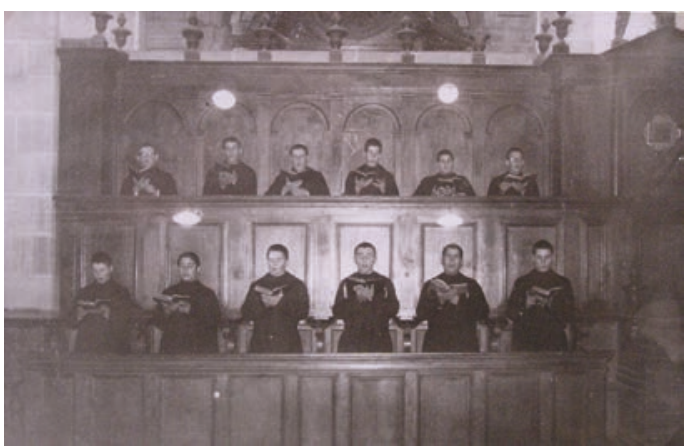

- Fig. 5. Parte del coro destinada a juniores y novicios, 9 de octubre de 1962. Fondo Fotográfico del Monasterio de Samos.

conservan hoy en día en el Archivo del Monasterio de $\mathrm{Samos}^{43}$. Todos ellos están firmados por Juan Monleón, a excepción de uno, de fecha desconocida y atribuido a Javier Liante $^{44}$. Bajo el título Coro y presbiterio de la iglesia abacial de Samos, el autor citado plan-

\footnotetext{
${ }^{41}$ Este miembro de la comunidad ya había sido el encargado de dirigir los trabajos de reconstrucción del monasterio tras el grave incendio sufrido el 24 de septiembre de 1951. A. ARMESTO: "Del fuego surge un nuevo Samos. El famoso monasterio benedictino, completamente restaurado, se inaugura próximamente", $A B C, 20$ de agosto de 1960, pp. 47-52.

${ }^{42}$ A. GARRIDO MORENO, Op. cit., p. 189.

${ }^{43}$ AMS, Proyecto de reconstrucción del monasterio tras el incendio de 1951, Carpetas V y VI.
}

${ }^{44}$ Ibídem, Carpeta V, Plano V-26, Coro y presbiterio de la iglesia abacial de Samos, sin fechar. 


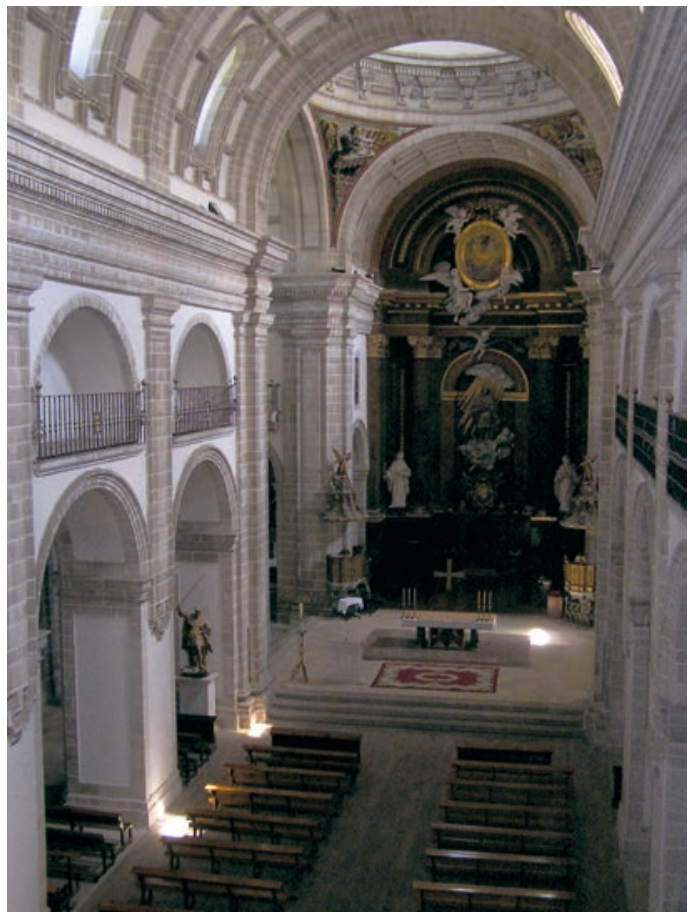

- Fig. 6. Interior de la nave central visto desde la tribuna, 28 de abril de 2012. Foto de la autora.

tea una primera solución de reordenación del espacio tras el traslado del coro al presbiterio y el desplazamiento del altar principal al centro del crucero. Esta propuesta es posiblemente anterior a las de Juan Monleón $\mathrm{y}$ creemos que fue tomada como referencia en ellas.

La primera solución dibujada por Juan Monleón para el traslado del coro y la reordenación del espacio litúrgico del templo de Samos está fechada en abril de $1960^{45}$. En ella se planteaba un único altar exento colocado en el espacio central del crucero, ligeramente retranqueado respecto del eje de la gran cúpula. El altar quedaba rodeado por un amplio presbiterio, que se extendía entre los cuatro grandes machones que soportan la cúpula de remate y en el mismo nivel que el presbiterio original. Esto obligaba a Juan Monleón a crear una plataforma ligeramente elevada respecto del nivel de las naves.

El coro se trasladaba al espacio de la cabecera, al fondo de la nave central e inme-

${ }^{45}$ Ibídem, Plano V-2, Real Abadía de Samos. Proyecto de reforma del coro, abril de 1960. diatamente detrás del nuevo altar principal. Se disponía formando una $U$ para conseguir una correcta visibilidad del aquel, con un total de 59 sitiales, frente a los 81 de la propuesta de Javier Liante. Por último, en esta primera solución, todavía se mantenía la reja de separación existente entre el espacio del nuevo presbiterio y el ámbito de la nave central, el que ahora se destina a los fieles.
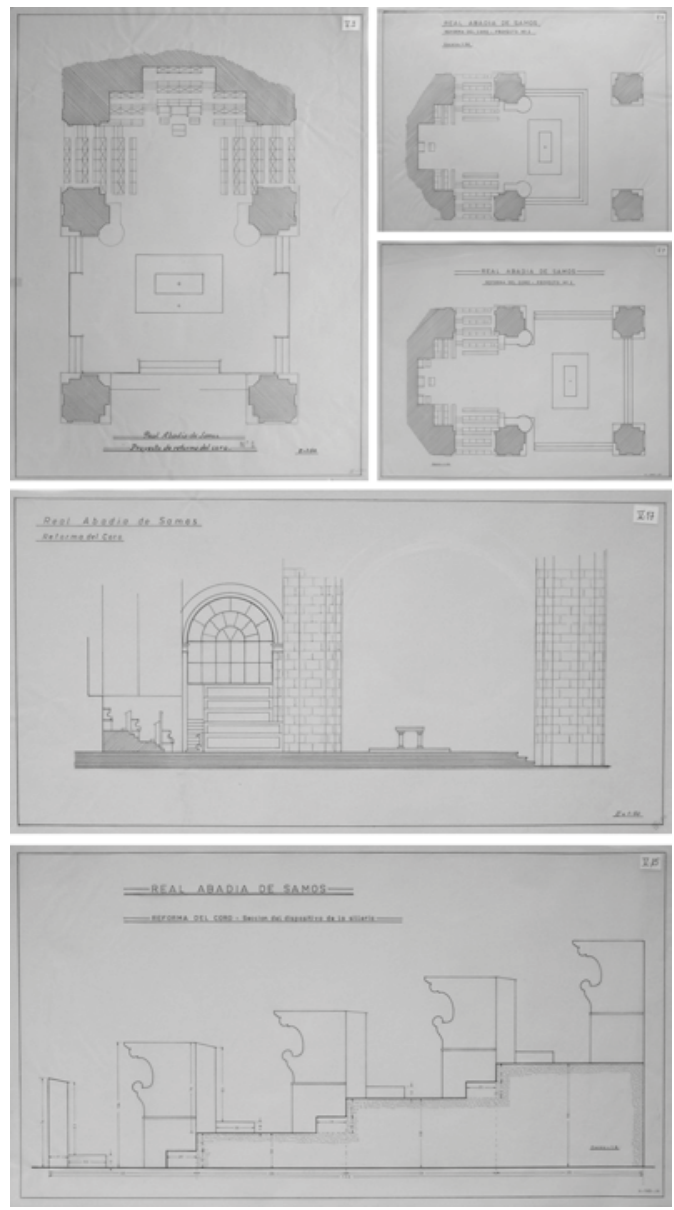

- Fig. 7. Los tres proyectos elaborados por Juan Monleón Sapiña para el traslado del coro al presbiterio, con algunos estudios en sección. AMS, Proyecto de reconstrucción del monasterio tras el incendio de 1951, Carpeta V, Planos V-2, V-3, V-7, V-15 y V-17.

El segundo proyecto es de mayo de $1965^{46}$. En él Juan Monleón variaba la posición del altar, más retranqueado respecto

${ }^{46}$ Ibídem, plano V-3, Real Abadía de Samos. Reforma del coro - Proyecto n⿳丷ㅡ, mayo de 1965. 


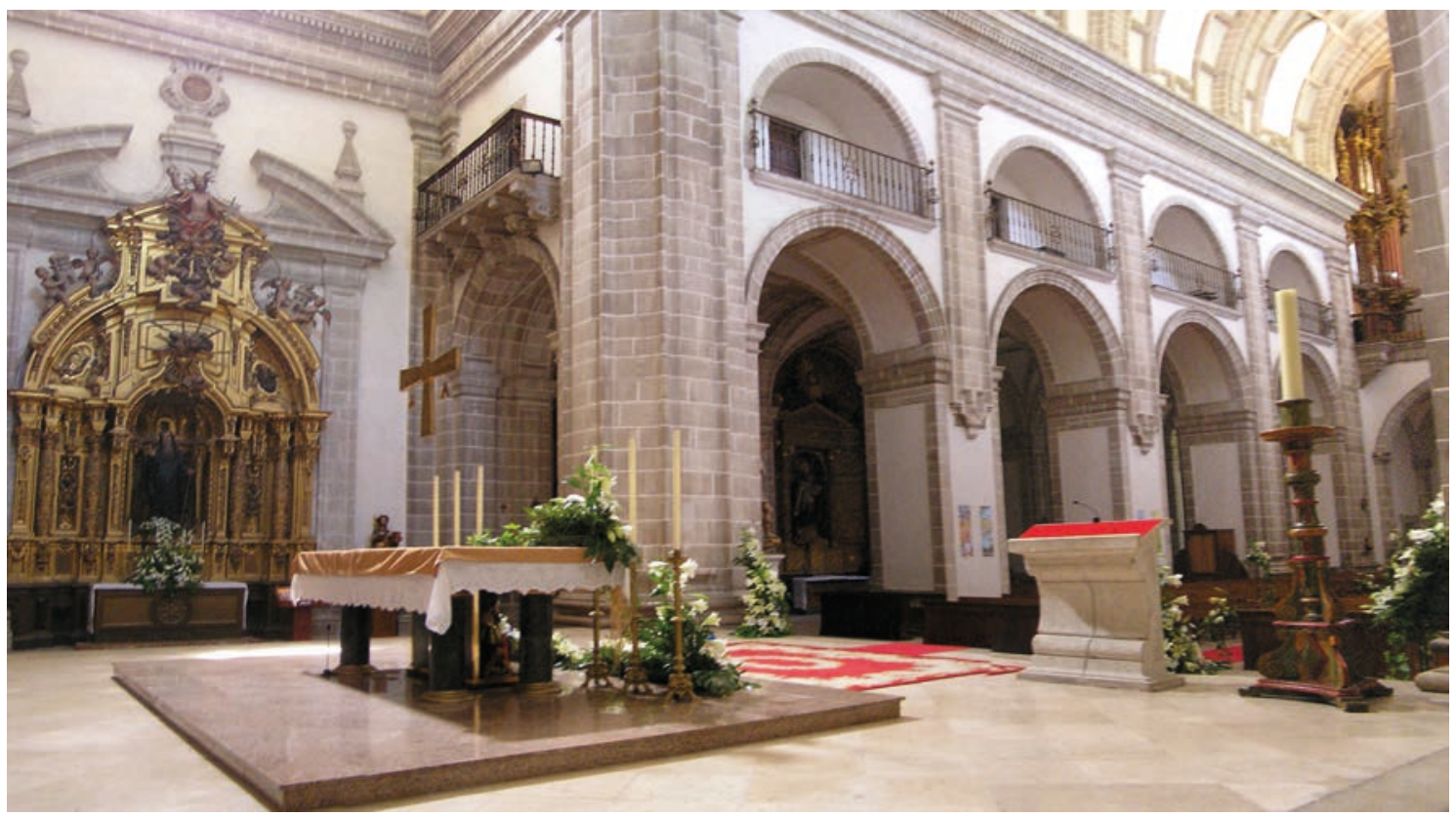

- Fig. 8. El presbiterio del templo tras la reforma visto desde un extremo del crucero, 22 de mayo de 2010. Foto de la autora.

del centro del crucero. La finalidad de este cambio era garantizar su visibilidad desde las últimas filas de asientos del coro. Asimismo, reducía la dimensión del presbiterio de forma considerable respecto de la primera solución planteada.

Además, este segundo proyecto contenía algunos cambios en la disposición de la sillería del coro, que afectaban principalmente a los sitiales ubicados justo debajo del retablo principal. Si bien en la solución de abril de 1960 eran tres las filas de sitiales dispuestas al fondo de la cabecera, bajo el retablo, en el proyecto de mayo de 1965 Juan Monleón sólo colocaba allí un asiento, el principal, reservado al abad. Esto implicaba una disminución considerable del número de sillas en el coro que se reducía hasta las 47 .

El proyecto definitivo, el número 3, es de junio de $1965^{47}$. En él se recuperaban algunos de los planteamientos de la solución de 1960. Así ocurría, por ejemplo, con el altar principal. Se resolvía como pieza exenta, dispuesta en el centro del crucero, bajo el eje

\footnotetext{
${ }^{47}$ Ibídem, Plano V-7, Real Abadía de Samos. Reforma del coro - Proyecto n⿳⺈ 3, junio de 1965.
}

de la gran cúpula que corona este espacio. Así se cumple con el principio conciliar de ser un altar separado de la pared, de modo que se puede girar a su alrededor y celebrar la liturgia hacia los fieles. Por otra parte, su posición es la más importante en el interior del templo, el centro al que se dirige, de forma espontánea, la atención de los asistentes a la liturgia.

El presbiterio del proyecto final recupera las amplias dimensiones del primer planteamiento, ocupando la mayor parte del espacio existente entre los cuatro machones que sostienen la cúpula y separándose, ligeramente, de los dos púlpitos. Se resolvió en el mismo nivel que la cabecera, por tanto, algo elevado respecto del resto del espacio del templo, lo cual obligó a crear escalones de acceso y ayuda a focalizar la atención (Fig. 8).

En cuanto al coro de los monjes, se mantuvo la disposición en forma de $\mathrm{U}$ de la sillería, con cuatro filas de asientos a cada lado, dos pequeñas filas en los ángulos y, bajo el retablo mayor, tres sitiales presidenciales, sumando un total de 51 sitiales (Fig. 9). 


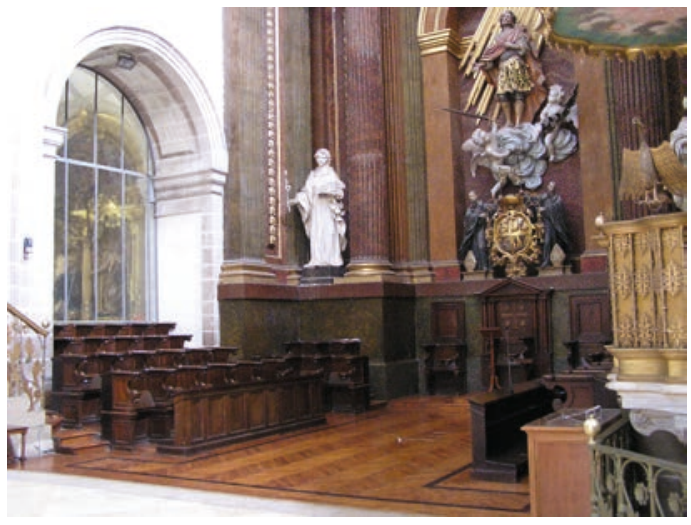

- Fig. 9. El nuevo coro de los monjes tras el traslado, 22 de mayo de 2010. Foto de la autora.

Con este proyecto se daba respuesta a los principios de la reforma litúrgica posconciliar. El espacio de celebración respondía así a factores como la correcta disposición de los asientos de los fieles, la amplitud del espacio litúrgico y la adecuada visibilidad. El traslado del coro al antiguo presbiterio liberaba el espacio de la nave central. Con ello se conseguía la superficie necesaria para los nuevos bancos de los fieles. Por otra parte, la eliminación de toda la estructura del coro original garantizaba una correcta visibilidad, basada no sólo en que todos los participantes de la ceremonia pueden ver el área donde ésta se celebra sino, sobre todo, en la sensación de que todos se sientan cercanos entre sí, algo que no permitía la disposición tradicional y que las nuevas instrucciones conciliares, anteriormente analizadas, indicaban como punto fundamental de la renovación litúrgica (Fig. 10).

Además de la organización del espacio interior del templo, Juan Monleón proyectó todos y cada uno de aquellos nuevos elementos que formaban parte de ella. De junio de 1965 es el diseño del nuevo altar exento de piedra, sobre tarima de losas de mármol dispuestas en forma de ajedrezado ${ }^{48}$. El di-

48 Ibídem, Plano V-19, Real Abadía de Samos. Proyecto de altar - (Proyecto “B”), junio de 1965; Plano V-21, Real Abadía de Samos. Tarima para el altar del proyecto "B", junio de 1965; Plano V-22, Real Abadía de Samos. Mesa y columna para altar - Proyecto “B”, junio de 1965; Plano V-23, Real Abadía de Samos. Mesa para altar. Detalles metálicos de las columnas (secciones),

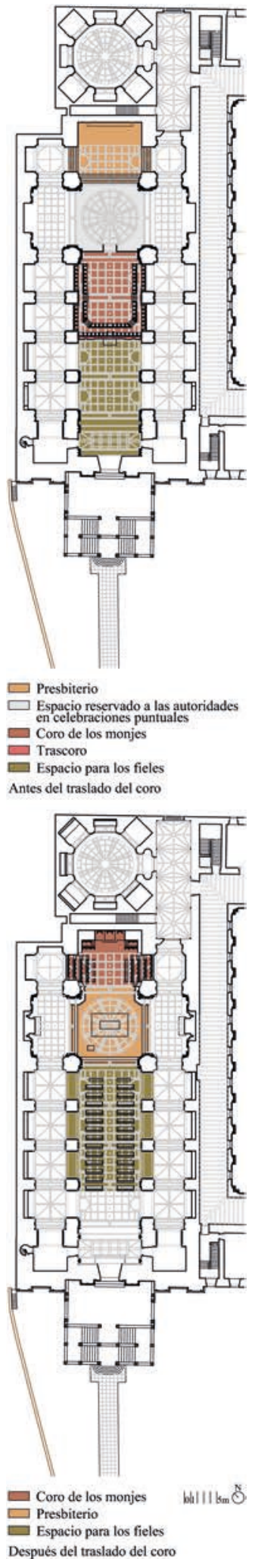

- Fig. 10. Estudio comparativo de la organización del interior del templo de Samos antes y después del traslado del coro en la segunda mitad del siglo XX. Planos elaborados por la autora. 
seño de la nueva peana o ambón para la proclamación de las lecturas sagradas es de agosto de $1967^{49}$. Se sitúa a la derecha del altar, próximo al espacio destinado a los fieles, pero dentro del ámbito correspondiente al presbiterio.

Entre los numerosos planos conservados de la reforma de la iglesia efectuada en estos años figuran diseños muy diversos, como las nuevas barandillas de los ante-púlpitos, un velorio, un candelabro, un candelero para el cirio pascual, un confesionario, los bancos para los fieles y un sagrario ${ }^{50}$.

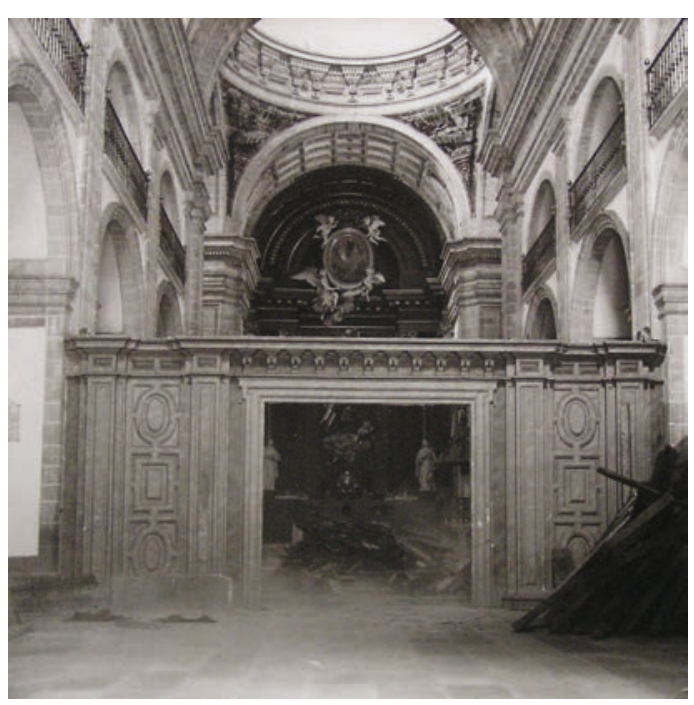

- Fig. 11. El desmantelamiento del coro de Samos, julio de 1967. Fondo Fotográfico del Monasterio de Samos.

Una vez que el proyecto y sus elementos estaban diseñados, los trabajos de des-

junio de 1965; Plano V-24, Real Abadía de Samos. Capitel y base para columna - (Proyecto "B"), junio de 1965.

${ }^{49}$ Ibídem, Carpeta VI, Plano VI-3, Real Abadía de Samos. Proyecto de peana, agosto de 1967.

${ }^{50}$ Ibídem, Carpeta V, Plano V-29, Barandilla para la iglesia (Ante-púlpitos), mayo de 1968; Carpeta VI, Plano VI-5, Real Abadía de Samos - Velorio, enero de 1967; Plano VI-6, Candelabro para diez blandones, noviembre de 1966; Plano VI-7, Real Abadía de Samos. Candelero para cirio pascual, mayo de 1965; Plano VI-9, Proyecto de confesionario, junio de 1970; Plano VI-11, Real Abadía de Samos. Bancos para la iglesia, sin fechar; Plano VI-12, Proyecto de sagrario, sin fechar.

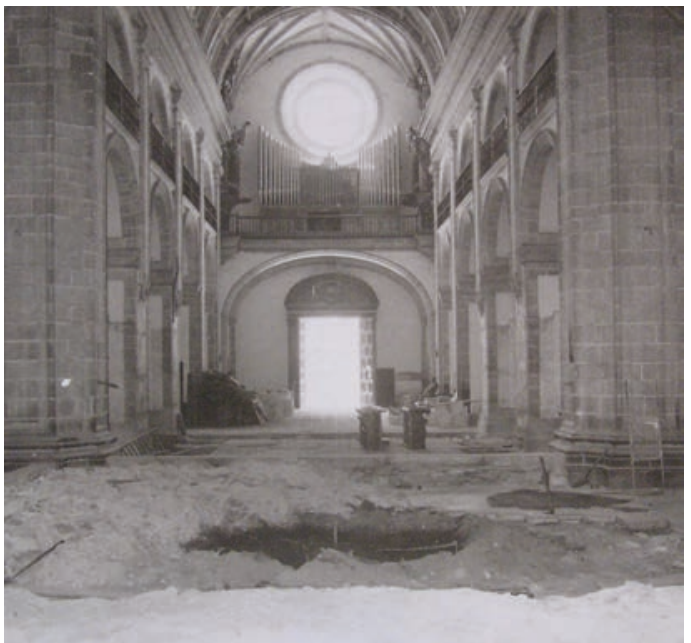

- Fig. 12. La nave central y parte del crucero durante las obras de traslado del coro y la construcción de un nuevo presbiterio, julio de 1967. Fondo Fotográfico del Monasterio de Samos.

montaje y traslado del coro comenzaron en julio de 1967 (Figs. 11 y 12) ) $^{51}$. En el mes de septiembre de ese mismo año Juan Monleón diseñó los nuevos pavimentos, de tarima de madera en la zona del $\operatorname{coro}^{52}$ y de losas de mármol en el nuevo presbiterio ${ }^{53}$. Asimismo, proyectó las grandes superficies de vidrio y armadura metálica que cierran el espacio del coro respecto de las naves laterales ${ }^{54}$.

Entre los planos conservados no figura, sin embargo, el diseño de los sitiales del coro de los monjes, a excepción de la llamada silla coral del preste, fechada en noviembre de $1961^{55}$. Esto nos lleva a pensar que se aprovecharon los asientos antiguos, aunque adaptados a su nueva posición y distribución. Entre las notas de Juan Monleón para la reforma del templo, encontramos la referencia a

${ }^{51}$ M. ARIAS CUENLLAS, Op. cit., p. 506.

${ }^{52}$ AMS, Proyecto de reconstrucción del monasterio tras el incendio de 1951, Carpeta V, Plano V-9, Real Abadía de Samos. Enrastrelado del coro, septiembre de 1967.

53 Ibídem, Plano V-10, Real Abadía de Samos. Pavimento del presbiterio, septiembre de 1967.

${ }^{54}$ Ibídem, Planos V-27 y V-28, Real Abadía de Samos. Reforma del coro. Armadura para cristales, septiembre y noviembre de 1967 .

55 Ibídem, Plano V-13, Silla coral del preste, noviembre de 1961. 
la existencia de 64 sillas en el coro original ${ }^{56}$, que fueron reducidas a 51 en el actual.

Las obras de reforma del espacio interior de la iglesia de Samos concluyeron en 1970, quedando consagrado el nuevo altar el 15 de enero ${ }^{57}$. Tras esta fecha, de Juan Monleón sólo conservamos el diseño de un nuevo rosetón para la iglesia, ejecutado y colocado en septiembre de $1971^{58}$.

\section{REFLEXIÓN FINAL}

A través de este trabajo hemos querido, en definitiva, recuperar la memoria de uno de tantos coros españoles hoy trasladados, desaparecidos, reformados o mutilados a lo largo del siglo pasado, con el propósito de mostrar de una forma lo más clara posible el valor del espacio arquitectónico perdido. Un espacio construido para dar respuesta a las necesidades de una época determinada y de un modo concreto de entender la liturgia.

El traslado del coro de Samos de la nave central a la cabecera supuso, como en otros muchos casos, un vacío importante. Asimismo, representa una falta de comprensión del carácter singular de ese espacio, no tanto por la calidad de sus elementos, sino más bien por su significado y función dentro del conjunto del proyecto originalmente diseñado.

Los argumentos en los que se apoyó esta operación fueron el de aumentar la capacidad del templo y el de ganar en visibilidad del altar. Para alcanzar esos propó-

${ }^{56}$ El número de sitiales del coro original no está claro. Si atendemos a la documentación histórica, en el inventario de 1836 al que hemos hecho referencia se habla de 65 sillas en total. No obstante, Castro señalaba, en 1912, que existían 56 sillas en el coro de los monjes. Por otra parte, si contamos el número de asientos dibujados en el plano de Durán de 1947 vemos un total de 66, mientras que Juan Monleón hace referencia entre sus notas del proyecto de reforma a 64 sillas en el coro original. AMS, Proyecto de reconstrucción del monasterio tras el incendio de 1951, Carpeta V, Croquis, sin fechar.

${ }^{57}$ M. ARIAS CUENLLAS, Op. cit., p. 506.

${ }^{58}$ AMS, Proyecto de reconstrucción del monasterio tras el incendio de 1951, Carpeta VI, Plano VI-14, Dibujo de rosetón, sin fechar. sitos no importó estropear la arquitectura, traicionar el proyecto original, destruir el trascoro, situar los sitiales alterados en la cabecera, dejar la nave sin contenido, destruir la reja o montar en otro lugar las esculturas que coronaban el trascoro ${ }^{59}$. En definitiva, no importó romper el valor que como conjunto tenían los sitiales, el trascoro, la reja y todos los otros elementos que constituían el coro de Samos colocados en el lugar adecuado dentro del espacio para el que fueron concebidos.

\section{BIBLIOGRAFÍA}

ARIAS ARIAS, P., Historia del Real Monasterio de Samos, Santiago de Compostela, 1950.

ARIAS CUENLLAS, M., Historia del monasterio de San Julián de Samos, Samos, 1992.

CASTRO, M., "Un monasterio gallego", Boletín de la Comisión Provincial de Monumentos Históricos y Artísticos de Orense, IV, no 85, 1912, pp. 192-194.

CASTRO FERNÁNDEZ, B. M., Francisco Pons-Sorolla y Arnau, arquitecto-restaurador: sus intervenciones en Galicia (19451985), Santiago de Compostela, 2007.

DURÁN, M., La Real Abadía de San Julián de Samos: estudio histórico-arqueológico, Madrid, 1947.

GARRIDO MORENO, A., "Juan Monleón Sapiña. Proxectos e reformas no mosteiro de Samos (1951-1976)", en M. C. FOLGAR DE LA CALLE y A. E. GOY DIZ (dirs.), San Xulián de Samos: Historia e arte

${ }^{59}$ Como consecuencia del desmontaje del trascoro, las imágenes de los abades Argerico y Ofilón, sosteniendo el escudo del monasterio, se recolocaron en la parte central inferior del retablo mayor del templo, exactamente sobre el asiento del coro correspondiente al abad de la comunidad monacal. Las imágenes de los reyes Fruela I y Alfonso II el Casto también fueron montadas en otro lugar. Cada una de ellas se dispuso sobre un pedestal de piedra, pegado a cada uno de los dos machones que soportan el arco que comunica el primer tramo de la nave central con el crucero. $\mathrm{M}$. ARIAS CUENLLAS, Op. cit., p. 277; I. REGA CASTRO, Op. cit., p. 212. 
nun mosteiro. Opus Monasticorum III, Santiago de Compostela, 2008, pp. 181-191.

LÓPEZ SALAS, E., “Propuesta metodológica para la restitución de la planimetría de una arquitectura medieval desaparecida: la iglesia románica del monasterio de San Julián de Samos (Lugo)", Arqueología de la Arquitectura (en línea), no 10, e002, Madrid/Vitoria, 2013, consultado el 21 de abril de 2014. URL: http://dx.doi. org/10.3989/arq.arqt.2013.008.

LÓPEZ VÁZQUEZ, J. M. B., “Os retablos neoclásicos do mosteiro de Samos", en M. C. FOLGAR DE LA CALLE y A. E. GOY DIZ (dirs.), San Xulián de Samos: Historia e arte nun mosteiro. Opus Monasticorum III, Santiago de Compostela, 2008. pp. 223-237.

NAVASCUÉS PALACIO, P., Teoría del coro en las catedrales españolas, Madrid, 1998.

"Coros y sillerías: un siglo de destrucción", Descubrir el Arte, no 15, 2000, pp. 112-114.

"Los coros catedralicios españoles", en R. YZQUIERDO PERRÍN (ed.), Los coros de catedrales y monasterios: arte y liturgia, A Coruña, 2001, pp. 23-41.

DE LA PORTILLA COSTA, P., Monasterio de Samos Guía histórico-artística, Lugo, 1978. El monasterio de Samos, Madrid, 1984.
“San Julián de Samos", en Monasterios de España, Madrid, 1988, pp. 25-88.

Monasterio de San Julián de Samos. Historia de dos restauraciones (1880 y 1951), A Coruña, 2003.

REGA CASTRO, I., "A(s) igrexa(s) de San Xulián de Samos. O seu amoblamento durante o Barroco", en M. C. FOLGAR DE LA CALLE y A. E. GOY DIZ (dirs.), San Xulián de Samos: Historia e arte nun mosteiro. Opus Monasticorum III, Santiago de Compostela, 2008, pp. 209-222.

Secretariado Nacional de Liturgia (ed.), $D i$ rectorio litúrgico-pastoral sobre ambientación $y$ arte en el lugar de la celebración, Madrid, 1987.

TEIJEIRO SANFIZ, B., Breve reseña históricodescriptiva de la Catedral de Lugo, las iglesias de Santo Domingo y San Francisco, pertenecientes a los conventos del mismo nombre, y del monasterio de san Julián de Samos, Lugo, 1887.

VILLASEÑOR SEBASTIÁN, F., TEIJEIRA PABLOS, M. D., MULLER, W. y BILLIET, F. (eds.), Choir Stalls in Architecture and Architecture in Choir Stalls, Newcastle upon Tyne, 2015.

YZQUIERDO PERRÍN, R. (ed.), Los coros de catedrales y monasterios: arte y liturgia, A Coruña, 2001. 